Research Article

\title{
Goaf Gas Control Improvement by Optimizing the Adjacent Roadway Large-Diameter Boreholes
}

\author{
Wei Wang $\left(\mathbb{D},{ }^{1,2}\right.$ Zongxiang $\mathrm{Li}^{1}{ }^{1}$ and Hongming $\mathrm{Yu}^{2}$ \\ ${ }^{1}$ College of Safety Science and Engineering, Liaoning Technical University, Liaoning 123000, China \\ ${ }^{2}$ Division of Energy, Shuifa Group Co., Ltd., Jinan 25000, China \\ Correspondence should be addressed to Wei Wang; wangweiwyc@163.com
}

Received 16 May 2021; Accepted 5 July 2021; Published 22 July 2021

Academic Editor: Zou Quanle

Copyright (c) 2021 Wei Wang et al. This is an open access article distributed under the Creative Commons Attribution License, which permits unrestricted use, distribution, and reproduction in any medium, provided the original work is properly cited.

This study introduced gas control technology in goaf using adjacent roadway large-diameter $(550 \mathrm{~mm})$ boreholes to control gas accumulation in the upper corner of a fully mechanized working face in high-gas coal seams. The gas control process in the upper corner and gas interception in goaf by large-diameter boreholes was analyzed using the CFD model of the gas flow in goaf. The latter considered the control equation of gas flow, the established permeability model of goaf, and the gas emission law in goaf. Using the 2-105 working face of the Tenghui Coal Mine, Shanxi Province, China, as a case study, the distribution patterns of gas concentration and flow field in the goaf for various extraction flow parameters and different positions of boreholes were numerically simulated. The dependences between various locations, drainage flows, and the gas concentration in the upper corner were determined and fitted by engineering equations. The evolution pattern of the spontaneous combustion zone in the goaf under the drainage conditions was also analyzed. The optimal borehole configuration parameters ensuring the extraction flow rate exceeding $3 \mathrm{~m} \cdot \mathrm{s}^{-1}$ and the effective gas control in the upper corner of the working face at a distance of $5 \mathrm{~m}-15 \mathrm{~m}$ behind the working face were identified. The engineering practice proved the feasibility of gas control in the goaf using the adjacent roadway large-diameter borehole. The gas concentrations in the return airflow and the upper corner of the working face were kept below 0.65 and $0.8 \%$, respectively, to ensure production safety and improve the gas utilization efficiency.

\section{Introduction}

Despite the global trend of green energy promotion, coal resources remain vital to industrial development, accounting for over half of China's power production. With increased mining intensity and burial depth, the coal seam's gas content also keeps increasing. Various low-gas mines have been converted into high-gas ones, with large gas emissions from the working face, and the gas accumulation in the upper corner often exceeds the limit. The gas emission is hazardous and restricts safe coal production. Meanwhile, mining gas utilization via an extraction system is lucrative from the green energy standpoint [1].

To mitigate the mine gas emission and utilization problems, great efforts have been invested in researching the goaf's gas flow. Majdi et al. studied the calculation method of the caving zone's height in the goaf [2]. Guo et al. proposed the annular fault zone formed above the goaf, constituting the gas accumulation and migration channels [3]. Zhang and Huang derived gas diffusion law in the goaf by studying the gas flow field in the goaf [4]. Zhou et al. applied the twodimensional model to simulate the fracture's gas flow under mining [5]. Karacan and Esterhuizene developed a comprehensive "dynamic" gas reservoir model by coupling the permeability field with the mechanical model to simulate the effects of gas emission and extraction on gas production in the goaf [6]. Wang et al. proposed a method to reduce the gas content and prevent gas outbursts using the large-diameter borehole gas extraction [7]. Yuan et al. introduced a theory and technology of using large-diameter surface boreholes to control the gas in the goaf, which was successfully implemented in the Huainan Mining Area of China [8]. However, theoretical studies [2-6] on the gas distribution and flow evolution in the goaf provided no practical solutions to the 
gas problems arising in the coal mining process. On the other hand, available recommendations for gas control in the goaf proposed in $[7,8]$ envisaged long construction periods, lacked flexibility and mobility, and failed to solve the problem of gas overrun in the upper corner of the mining face caused by abnormal changes in geological conditions or airflow and abnormal gas emission. Based on the available theoretical achievements, this paper proposes the gas control in the goaf using a large-diameter borehole constructed in the adjacent roadway of the working face. This technology, characterized by high flexibility and productivity, adopts an improved geological drilling machine, producing a largediameter $(550 \mathrm{~mm})$ extraction borehole. The drilling parameters can be easily adjusted, according to particular geological conditions, changes in airflow, and abnormal gas emission. In combination with existing gas control measures, the proposed approach mitigates the problem of local gas accumulation in the working face of high-intensity mining quickly, efficiently, and accurately.

\section{Background and Specific Features of the Adjacent Roadway Large-Diameter Drilling Extraction}

2.1. Background and Aims of the Proposed Approach. Under the "U-shaped" ventilation mode, the upper corner of the fully mechanized working face in the high-gas coal seam is close to the coal wall and the goaf side; the airflow velocity is very low, and some areas are in the eddy current state. The gas emitted from the goaf circulates near the upper corner and accumulates in the eddy current area. At the same time, the continuous emission of high-concentration gas in the goaf due to air leakage in the working face provides a high amount of gas in the upper corner, easily reaching an overrun state [9]. At present, the common measures taken to mitigate this problem are as follows. The first one is to change the ventilation mode [10] to prevent the gas from forming the eddy current in the upper corner of the working face. The second one envisages the promoted preextraction of the coal seam [11] and reduces gas emissions from the mining seam. The third one is to control the gas in the goaf via pipe burying or spline extraction in the goaf, high-level drilling or roadway extraction, surface drilling extraction [12], etc. These measures are characterized by a long construction period and high costs. Especially in the case of sudden local gas accumulation, a long time is needed for adjustment. Therefore, it is necessary to use rapid, efficient, flexible, and low-cost techniques to reduce local gas accumulation.

\subsection{Advantages of the Adjacent Roadway Large-Diameter} Extraction. The large-diameter gas extraction boreholes of adjacent roadway construction at the air-return side of the working face shown in Figure 1 can change the eddy current formed at the upper corner of the working face into the original flow field of the goaf, introduce new disturbance, extract the goaf gas in the form of large flow and low negative pressure, and intercept the gas from the goaf due to the air leakage of the working face to solve the problem of local gas overrun. This technology features mechanized operation, simple process, and low engineering complexity, which can effectively solve the problem of connection and balance of mine "mining and extraction" in terms of time. The borehole spacing and the number of boreholes can be adjusted at any time with the working face advance. With strong flexibility, it can exert an effective interception effect on the emitted goaf gas. The key issue of this technology application is to determine the optimal drilling configuration parameters. The computational fluid dynamics (CFD) numerical simulation can be used to determine the gas concentration field and flow field distribution pattern of the goaf at various large-diameter boreholes' parameters. Then, the drilling configuration design can be optimized to get the best extraction parameters. The technology of large-diameter drilling in the adjacent roadway to control the goaf is illustrated in Figure 1. A gas drainage process is schematically presented in Figure 1(a), where the extracted gas (i.e., coalbed methane or CBM) is transported via pipelines, with an improved utilization rate of energy resources and environmental protection. Figures 1(b)-1(d) show the specific construction equipment and technology of gas drainage.

\section{Numerical Simulation of Large-Diameter Drilling Extraction}

3.1. Theories of Goaf Gas Migration. Under the mining and the overlying rock pressure, the size of voids in the goaf exhibits certain trends in the vertical and strike directions. In the vertical direction, the caving zone, fracture zone, and bending subsidence zone are formed [13]. In the strike direction, with different accumulation states and pressure on the coal and rock mass, three areas are formed: the natural accumulation area, the caving load area, and the recompaction area [14]. During the coal seam mining process, the goaf loses its supporting force, and a considerable number of secondary fissures are formed in the caving zone and the fracture zone, which become the main gas migration channels. The coal and rock mass in the caving zone is filled with a considerable amount of broken coal and rock mass, resulting in larger porosity. The fracture zone has a smaller porosity due to the support of the caving zone. The goafs porosity shows nonuniform continuous distribution characteristics [15] and presents an O-shaped distribution, as shown in Figure 2.

The height of the fracture and caving zones in the goaf can be obtained through physical analog modeling, numerical simulation, field observations, and theoretical calculations [16]. Determination of these values is conducive to analyzing the physical properties and gas flow characteristics of the goaf. It can provide basic support for the establishment of CFD numerical analysis. According to the law of movement and failure of the overlying coal and rock mass in the goaf, the caving zone and the fracture zone in the goaf can be calculated as follows: 


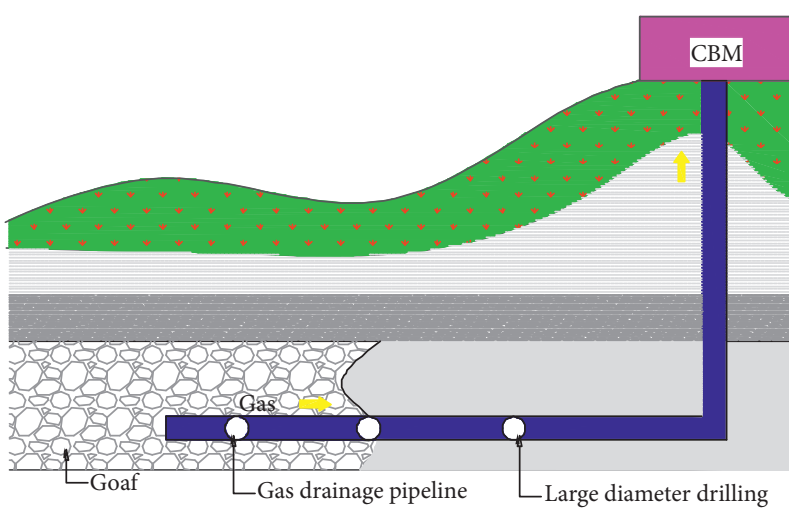

(a)

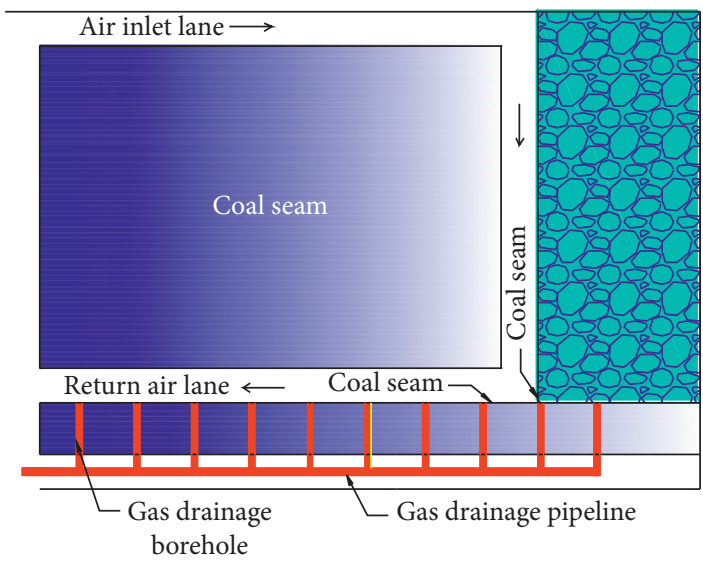

(c)

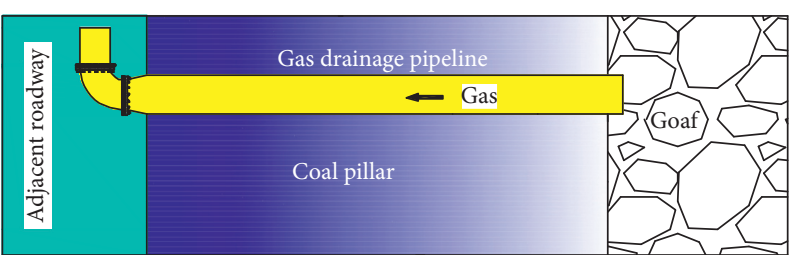

(b)

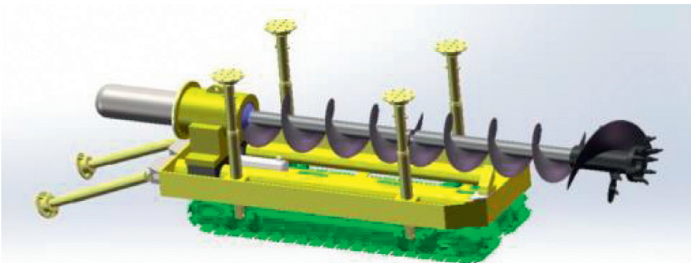

(d)

Figure 1: Schematic diagram of the large-diameter drilling extraction. (a) Gas drainage diagram. (b) Section diagram of extraction borehole. (c) Plane diagram of extraction drilling. (d) Schematic diagram of drilling rig.

$$
\begin{aligned}
& H_{k}=\frac{H-W}{\left(K_{p b}-1\right)} \pm c, \\
& H_{l}=\frac{100 H}{a H+b} \pm c,
\end{aligned}
$$

where $H_{k}$ is the caving zone height, $H$ is the mining height, $W$ is the main roof subsidence, $K_{p b}$ is the crushing expansion coefficient of the caving rock, and $\alpha$ is the dip angle of the coal seam, while $a, b, c$ are the coefficients related to the roof properties, which can be determined according to the empirical formula in [5].

According to the "O"-ring theory, the goafs porosity distribution gradually increases from the goaf's edge to the central compaction area. Based on the mathematical model of a continuous surface of the subsidence of the stope overburden, the porosity distribution model of the caving zone in the goaf has been theoretically deduced [17] in the following form:

$$
n(x, y)=1+\left(\left(1+e^{-0.15\left(l_{y}-|y|\right)}\right)\left(1-\frac{h_{d}}{h_{d}+\left(H-h_{d}\left(K_{p b}-1\right)\left(1-e^{-(x / 2 l)}\right)\right)}\right)-1\right)\left(1+\beta \gamma\left(\frac{l_{y}}{2}-y\right) \sin \alpha\right)^{-1}
$$

where $n$ is the porosity of any point, $\gamma$ is the volume weight of the caving rock, $\alpha$ is the dip angle of the coal seam, $l_{y}$ is the dip width of goaf, $\beta$ is the regression coefficient, $h_{d}$ is the thickness of the immediate roof, and $l$ is the length of the broken rock block of the main roof.

For the convenience of calculation, the following assumptions are made for the goaf in this study [18]:
(1) The shearer and all kinds of equipment of the hydraulic prop in the fully mechanized top coal caving face are ignored; only the air leakage from the working face into the goaf is calculated for the goaf gas, and the return air roadway and extraction drilling on gas emission and concentration distribution are studied. 
(2) The working face, the inlet, and return air roadways are assumed to be cuboids filled with an incompressible ideal gas.

(3) The goaf is assumed to be porous and isotropic [19].

Therefore, the goaf's gas mixture flow satisfies the mass equation and the momentum equations [20].
The mass equation has the following form:

$$
\frac{\partial \rho}{\partial t}+\frac{\partial(\rho \mu)}{\partial x}+\frac{\partial(\rho \nu)}{\partial y}+\frac{\partial(\rho w)}{\partial z}=0 .
$$

The momentum equations can be expressed as follows:

$$
\begin{gathered}
\frac{\partial(\rho \mu \mu)}{\partial x}+\frac{\partial(\rho \mu v)}{\partial y}+\frac{\partial(\rho \mu w)}{\partial z}=\frac{\partial}{\partial x}\left(\mu \frac{\partial \mu}{\partial x}\right)+\frac{\partial}{\partial y}\left(\mu \frac{\partial \mu}{\partial y}\right)+\frac{\partial}{\partial z}\left(\mu \frac{\partial \mu}{\partial z}\right)-\frac{\partial p}{\partial x}+S_{u} \\
\frac{\partial(\rho v \mu)}{\partial x}+\frac{\partial(\rho v v)}{\partial y}+\frac{\partial(\rho v w)}{\partial z}=\frac{\partial}{\partial x}\left(\mu \frac{\partial v}{\partial x}\right)+\frac{\partial}{\partial y}\left(\mu \frac{\partial v}{\partial y}\right)+\frac{\partial}{\partial z}\left(\mu \frac{\partial v}{\partial z}\right)-\frac{\partial p}{\partial y}+S_{v} \\
\frac{\partial(\rho w \mu)}{\partial x}+\frac{\partial(\rho w v)}{\partial y}+\frac{\partial(\rho w w)}{\partial z}=\frac{\partial}{\partial x}\left(\mu \frac{\partial w}{\partial x}\right)+\frac{\partial}{\partial y}\left(\mu \frac{\partial w}{\partial y}\right)+\frac{\partial}{\partial z}\left(\mu \frac{\partial w}{\partial z}\right)-\frac{\partial p}{\partial z}+S_{w}
\end{gathered}
$$

The turbulent kinetic energy equation is

$$
\begin{aligned}
\frac{\partial(\rho k)}{\partial t}+\frac{\partial\left(\rho \mu_{i} k\right)}{\partial x_{i}}= & \frac{\partial\left[\left(\mu+\left(\mu_{t} / \sigma_{k}\right)\right) \partial k / \partial x_{j}\right]}{\partial x_{j}} \\
& +G_{k}+G_{b}-\rho \varepsilon-Y_{M}+S_{k}
\end{aligned}
$$

The transport equation of the turbulent dissipation rate is given below:

$$
\begin{aligned}
\frac{\partial(\rho \varepsilon)}{\partial t}+\frac{\partial\left(\rho \mu_{i} \varepsilon\right)}{\partial x_{i}}= & \frac{\partial\left[\left(\mu+\left(\mu_{t} / \sigma_{\varepsilon}\right)\right) \partial k / \partial x_{j}\right]}{\partial x_{j}} \\
& +C_{1 \varepsilon} \times \frac{\varepsilon}{k}\left(G_{k}+C_{3 \varepsilon} G_{b}\right)-G_{b}-C_{2 \varepsilon} \rho \frac{\varepsilon^{2}}{k}+S_{\varepsilon}
\end{aligned}
$$

where $\mu_{t}$ is the turbulent viscosity, $\mu_{i}$ is the time-averaged velocity, $\rho$ is the density, $G_{k}$ is the generic term of turbulent kinetic energy $k$ caused by the velocity gradient, $S_{\varepsilon}$ and $S_{k}$ are user-defined source terms, and $C_{1 \varepsilon}, C_{2 \varepsilon}$, and $C_{3 \varepsilon}$ are empirical constants.

If the goaf is regarded as the porous medium, it possesses the additional (viscous and inertial) resistance to the gas mixture in the goaf. By adding the loss term in the momentum equation, including viscous resistance and inertial resistance, the following equation is obtained:

$$
S_{i}=\frac{\mu v_{i}}{k}+0.5 C_{2} \rho v_{i}\left|v_{i}\right|
$$

where $k$ is the goaf permeability (the reciprocal of viscous resistance), $\mu$ is the dynamic viscosity, $v_{i}$ is the velocity component in direction $i$, and $C_{2}$ is the inertia resistance coefficient. Due to the small air leakage in the goaf, the inertia resistance is usually neglected.

As shown in equation (7), permeability is the key parameter for simulating the goaf gas migration law. According to Darcy's law [21], the permeability model can be represented by the Kozeny-Carman equation [22, 23] in the following form:

$$
k=\frac{D_{p}^{2}}{180} \cdot \frac{n^{3}}{(1-n)^{2}},
$$

where $D_{p}$ is the average particle size ranging from 0.014 to $0.016 \mathrm{~m}$ [24] and $n$ is the porosity of the porous medium.

Equation (8) constitutes the governing equation of the gas flow in the goaf. For the particular boundary and initial conditions, the gas flow pattern can be determined.

3.2. Gas Source Analysis. The gas emission in a fully mechanized working face can be calculated using the different-source prediction method, with the coal seam gas content used as the basic parameter [25]. It follows the principle of establishing an empirical formula based on years of detection data according to the gas content of coal seam, the gas gushing pattern of gas gushing source, the occurrence conditions, and mining technical conditions of coal seam [26]. The gas emission of each part is calculated to achieve the gas emission calculation.

Gas emission from a fully mechanized working face includes gas emissions from the mining seam, from the coal remaining in the goaf, and from the adjacent seam, as shown in Figure 3.

The calculation formula of gas emission in the mining seam $Q_{1}$ is as follows:

$$
Q_{1}=\lambda \cdot \frac{m}{H}\left(W_{0}-W_{c}\right),
$$

and that in the adjacent seam $Q_{2}$ is

$$
Q_{2}=\sum_{i=1}^{n}\left(W_{0 i}-W_{c i}\right) \cdot \frac{m_{i}}{H}
$$


The calculation formula of gas emission from the coal remaining in the goaf $Q_{3}$ is

$$
Q_{3}=l \cdot q_{0} \cdot v_{0}\left[\exp \left(-\sqrt{\frac{l_{1}}{v_{0} t}}\right)+\exp \left(-\sqrt{\frac{l_{2}}{v_{0} t}}\right)\right],
$$

where $\lambda$ is the gas emission coefficient, $W_{0}$ is the original gas content, $W_{c}$ is the residual gas content, $m$ is the mining seam thickness, $i$ is the parameter of the $i$-th adjacent seam, $l$ is the perimeter of the roadway fault face, $v_{0}$ is the advancing speed of the working face, $t$ is the exposure time of the coal seam (which is taken as six months), $l_{1}$ is the strike length of the working face, $l_{2}$ is the strike length of the goaf, and $q_{0}$ is the gas emission intensity of the coal wall. The latter parameter can refer to the calculation of coal wall gas emission in "Prediction method of mine gas emission" (AQ1018-2006):

$$
q_{0}=0.026 \cdot\left[0.0004\left(V^{f}\right)^{2}+0.16\right] \cdot W_{0},
$$

where $V^{f}$ is the volatile content in the coal, taken as $18.79 \%$.

\subsection{Details of Numerical Simulation}

3.3.1. Basic Parameters of the Working Face. The Tenghui Coal Mine is located in Xiahua Township, Hejin City, Shanxi Province, China, with the mine field located on the southern edge of the Hedong Coalfield. The strike longwall mining method is adopted for the working face. The average thickness of the coal seam is $5.2 \mathrm{~m}$, the widths of the inlet and return air roadway of the working face are $4 \mathrm{~m}$, the height is $3 \mathrm{~m}$, the length of the working face is $185 \mathrm{~m}$, the mining height is $3 \mathrm{~m}$, the mining width is $5 \mathrm{~m}$, the roof periodic weighting step is $15 \mathrm{~m}$, and the buried depth of the coal seam is $368-480 \mathrm{~m}$. The U-shaped ventilation mode is adopted. The lithology of the roof is sandy mudstone and mudstone, and the lithology of the floor is mudstone and sandy mudstone, which belongs to a medium-hard roof.

According to the previous basic theoretical analysis, the geological conditions of the Hedong Coalfield, the actual onsite test data of the Tenghui Coal Mine working face, the experimentally measured data, and the empirical parameters' values, the calculation formula parameters were obtained and are listed in Table 1. The physical parameters of the numerical model are summarized in Table 2.

3.3.2. Establishment of a Geometric Model of a Fully Mechanized Working Face. According to the actual situation in the coal mining face, the size and boundary conditions were set as follows:

(1) The size of inlet and return roadways was $10 \times 4 \times 3 \mathrm{~m}^{3}$, the size of the working face was $185 \times 5 \times 3 \mathrm{~m}^{3}$, and space was filled with fluid.

(2) The goaf size was $185 \times 200 \times 57 \mathrm{~m}^{3}$, in which the fracture zone was $40 \mathrm{~m}$, the caving zone was $17 \mathrm{~m}$, and space was a porous medium.

(3) Except for the inlet and return air roadways of the working face, all the outer boundaries of the extraction drilling were set as the "wall," and the interface between the working face and the goaf was set as the "interior." It was assumed that the stope had no material exchange or conditional reaction with the outside environment. The established geometric model is shown in Figure 4(a), and red arrows represent the model's corresponding coordinate system in Figure 2.

\subsubsection{Mesh Generation and Model Realization. (1) Mesh} Generation. The established physical model's calculation domain was meshed using a tetrahedral mesh, as shown in Figure 4(b).

The inlet and return air roadways' mesh sizes were both $0.5 \mathrm{~m}$, and those of the caving and fracture zones in the goaf were $2 \mathrm{~m}$ each. When the large-diameter borehole was connected to the goaf, spherical densification was carried out around the goaf, and the densified mesh size was $0.1 \mathrm{~m}$, as shown in Figure 4(c).

(2) Solver Setting. The gas concentration and flow field distribution in the goaf were numerically simulated at the borehole distances of $0,5,10,15$, and $20 \mathrm{~m}$ from the working face under the extraction-free and extraction conditions. It was assumed that the flow rate of the extraction borehole remained unchanged. The simulation conditions were as follows: the inlet velocity of $2.5 \mathrm{~m} \cdot \mathrm{s}^{-1}$ was set at the inlet of the inlet roadway, the "outlet flow" was set at the outlet of the return roadway, the inlet velocity of the large-diameter extraction borehole was $-5 \mathrm{~m} \cdot \mathrm{s}^{-1}$, the borehole diameter was $550 \mathrm{~mm}$, and the vertical distance from the floor was $2 \mathrm{~m}$.

When the goaf was treated as the porous medium, permeability was a parameter to be determined. In the fracture zone, the permeability variation range is usually between $10^{-6}$ and $10^{-11} \mathrm{~m}^{2}$ [27]. In this study, the porosity of the fracture zone was taken as a fixed value of 0.03 [28]. Substitution of this value into equation (8) yields the permeability range between $10^{-6}$ and $10^{-11}$. The porosity of the caving zone of the actual working face was substituted into equation (3) to get the porosity distribution, which had a "shovel" shape. This implies large porosity values of the shallow part and two roadway sides and small ones of the middle and inner parts, as shown in Figure 4(d). The porosity value was substituted into equation (8) to obtain the permeability parameters.

A user-defined function (UDF) was employed during the CFD numerical simulation to compile the caving zone's permeability. The "simple" algorithm was selected in the pressure-velocity coupling algorithm, and the renormalization group (RNG) K-epsilon $(k-\varepsilon)$ turbulence model [29] was adopted to simulate the gas flow mixture in the stope to improve the simulation accuracy.

\subsection{Analysis of Simulation Results for Various Conditions}

3.4.1. Analysis of Gas Migration Law in Goaf under Drainage Conditions. A coordinate system was established according to Figure 4, with the depth direction, the inclination direction, and the vertical direction of the goaf taken as the $X$-, 

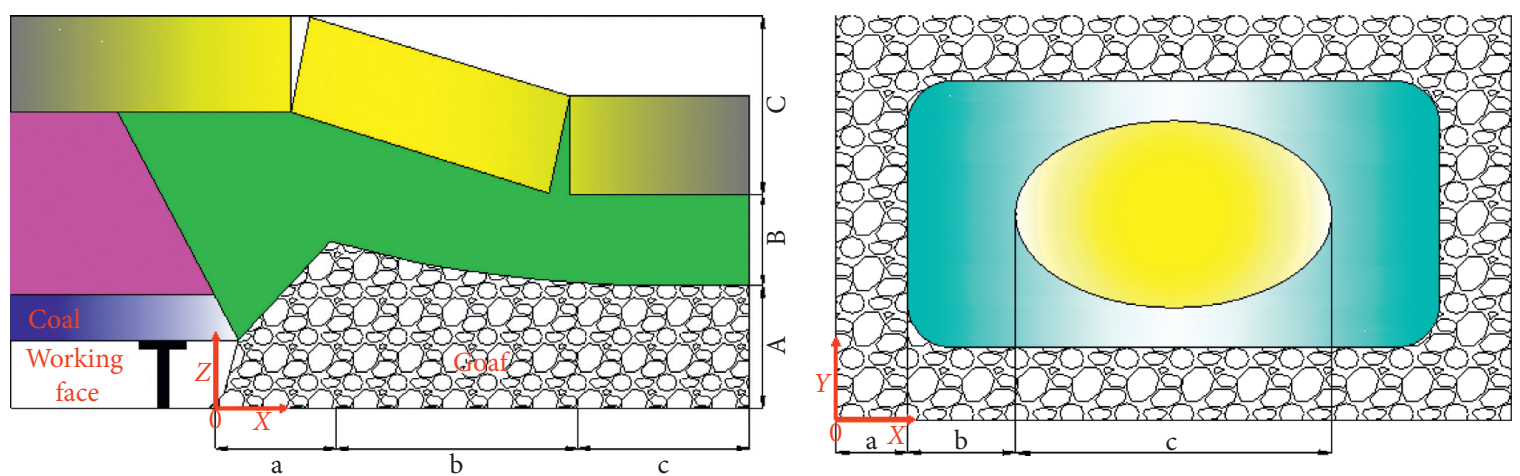

FiguRE 2: Diagram of three horizontal and three vertical zones in the goaf and the coordinate system of the proposed model. (A) Collapse zone. (B) Fracture zone. (C) Bending subsidence zone. (a) Natural accumulation area. (b) Load affected zone. (c) Compaction area.

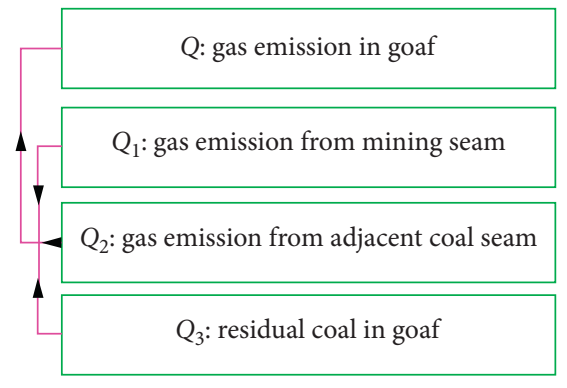

(a)

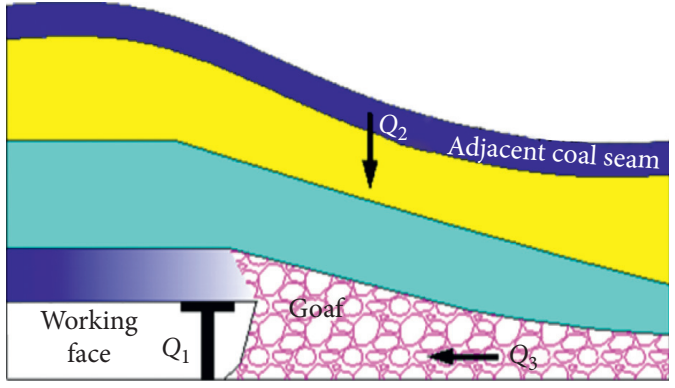

(b)

FIGURE 3: Gas source diagram of the working face. (a) Structure diagram of gas source in goaf. (b) Schematic diagram of gas source in goaf.

$Y$-, and $Z$-axes, respectively. The range of the $X$-axis $[-2 \mathrm{~m}$, 0 ] was regarded as the upper corner of the working surface. According to the coal mine safety regulations, $0.8 \%$ of the gas concentration in the upper corner is the critical value, while that below $0.8 \%$ is considered to be safe, implying the draining effectiveness.

The numerical simulation results of gas migration under the conditions of $Z=2 \mathrm{~m}$ and no extraction and large-diameter borehole extraction in the goaf area are illustrated in Figure 5. It can be observed from Figure 5(a) that due to air leakage from the working face, the airflow enters the goaf to bring the high-concentration gas in the goaf to the return air side and finally dilutes into the return airflow. Due to the coal wall effect, the air current forms a vortex near the upper corner of the working surface, causing local overrun, with the gas concentration exceeding $6 \%$. The deeper the goaf, the higher the gas concentration, up to $70 \%$, making the goaf a gas reservoir. Therefore, extraction measures must be taken to restrain the upper corner gas from exceeding the limit.

In this paper, simulation schemes with different flow rates and locations listed in Table 3 were designed to explore the impact of large-diameter boreholes on gas migration in goaf. The gas distribution law was obtained by comparison. According to the actual working conditions of the on-site extraction pump, the maximum extraction flow rate of the borehole was $100 \mathrm{~m}^{3} \cdot \mathrm{min}^{-1}$, indicating that the maximum flow rate of the mixed gas in the borehole was $7 \mathrm{~m} \cdot \mathrm{s}^{-1}$.
Other boundary conditions and the calculation process of the solver were the same as before. Besides, the gas concentration values in the large-diameter borehole and the upper corner were taken as dependent variables. The numerical simulation results are presented in Figure 6.

Best fitting of the numerical simulation results was performed, yielding the following formula:

$$
\begin{gathered}
c=0.489+\frac{0.667}{v}+6.62 e^{-6 y^{4}}+\frac{3.28}{y \cdot v}-0.00283 v \cdot y^{2}, \\
R^{2}=0.958,
\end{gathered}
$$

where $c$ denotes the gas concentration in the upper corner, $v$ is the extraction rate, and $y$ is the distance from the working face, while $R^{2}$ is the correlation coefficient, which the value is 0.958 that to indicate a close correlation.

As seen from the fitting formula, when the drilling position is fixed, the higher the extraction rate, the lower the gas concentration in the upper corner. When the extraction rate is constant, the farther the drilling position from the working surface, the higher the gas concentration in the upper corner.

As illustrated in Figure 6(a), with an increase in the extraction rate, the concentration in the gas pipeline gradually grows. The farther the borehole from the working 
TABLE 1: Calculation formula parameters' values.

\begin{tabular}{|c|c|c|c|}
\hline Symbol & Parameter & Value & Unit \\
\hline$a / b / c$ & Calculation parameters of the fracture zone & $1.5 / 3.6 / 5.6$ & \\
\hline$H$ & Mining height & 5.2 & $\mathrm{~m}$ \\
\hline$h_{d}$ & Thickness of immediate roof & 6 & $\mathrm{~m}$ \\
\hline$K_{p b}$ & Coefficient of rock crushing expansion of the caving zone & 1.049 & \\
\hline$l^{p o}$ & Length of main roof broken rock block & 8 & $\mathrm{~m}$ \\
\hline$l_{1}$ & Strike length of working face & 185 & $\mathrm{~m}$ \\
\hline$l_{2}$ & Strike length of goaf & 185 & $\mathrm{~m}$ \\
\hline$m$ & Thickness of mining seam & 5.2 & $\mathrm{~m}$ \\
\hline$q_{0}$ & Gas emission intensity of coal wall & 0.0503 & $\mathrm{~m}^{3} \cdot\left(\mathrm{m}^{2} \cdot \mathrm{min}\right)^{-1}$ \\
\hline$v_{0}$ & Advancing speed of the working face & $4.2 \times 10^{-3}$ & $\mathrm{~m} \cdot \min ^{-1}$ \\
\hline$W_{0}$ & Original gas content of coal seam & 12.1 & $\mathrm{~m}^{3} \cdot \mathrm{t}^{-1}$ \\
\hline$W_{c}$ & Residual gas content & 2.81 & $\mathrm{~m}^{3} \cdot \mathrm{t}^{-1}$ \\
\hline$\alpha$ & Coal seam dip angle & 0 & $\circ$ \\
\hline$\lambda$ & Gas emission coefficient & 1.34 & \\
\hline
\end{tabular}

TABle 2: Physical parameters of the numerical model.

\begin{tabular}{lccc}
\hline Symbol & Parameter & Value & \\
\hline$H_{l}$ & Height of the fracture zone & 40 & Unit \\
$H_{k}$ & Height of the caving zone & 17 & $\mathrm{~m}$ \\
$Q_{1}$ & Gas emission of the mining seam & $6.49 \times 10^{-6}$ & $\mathrm{~m}$ \\
$Q_{2}$ & Gas emission of the adjacent seam & $1.99 \times 10^{-9}$ & $\mathrm{~kg} \cdot\left(\mathrm{m}^{3} \cdot \mathrm{s}\right)^{-1}$ \\
$Q_{3}$ & Goaf gas emission amount & $1.71 \times 10^{-7}$ & $\mathrm{~kg} \cdot\left(\mathrm{m}^{3} \cdot \mathrm{s}\right)^{-1}$ \\
\hline
\end{tabular}

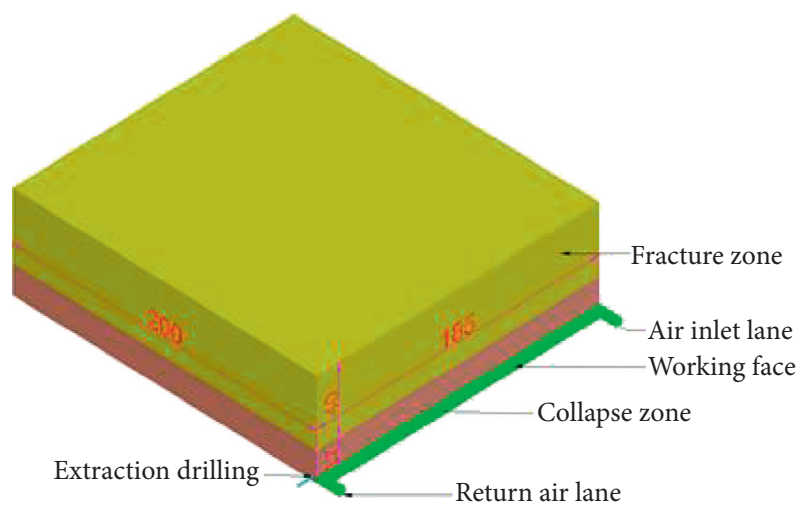

(a)

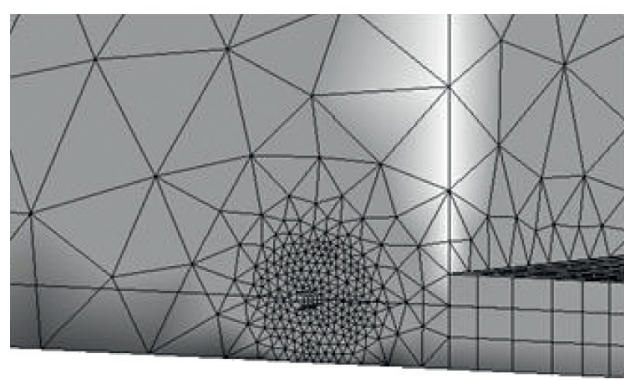

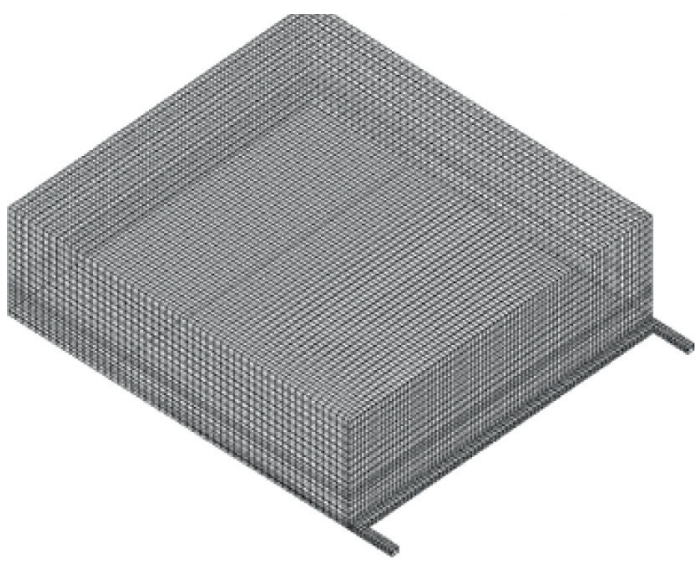

(b)

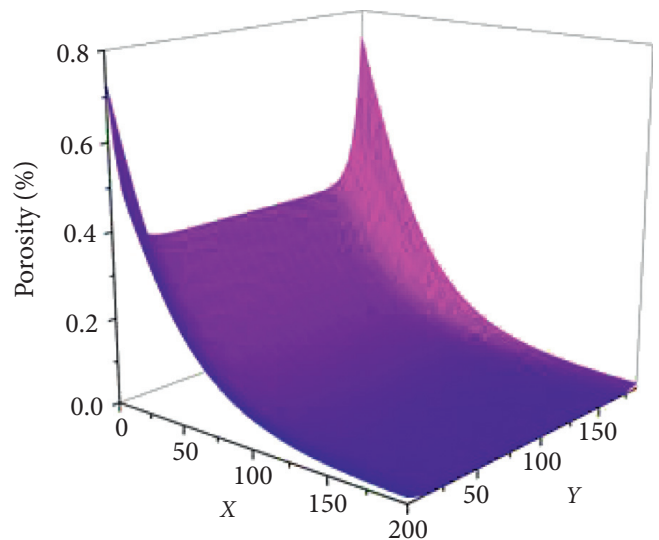

(d)

Figure 4: Numerical simulation model and porosity distribution of the caving zone. (a) Geometric model of working face. (b) Mesh generation of working face. (c) Distribution law of porosity in goaf. (d) Mesh generation of large-diameter borehole. 


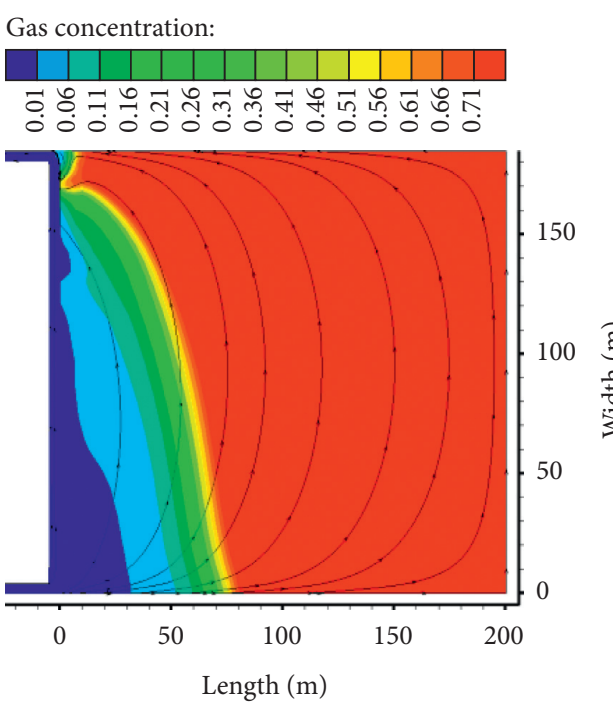

(a)
Gas concentration:

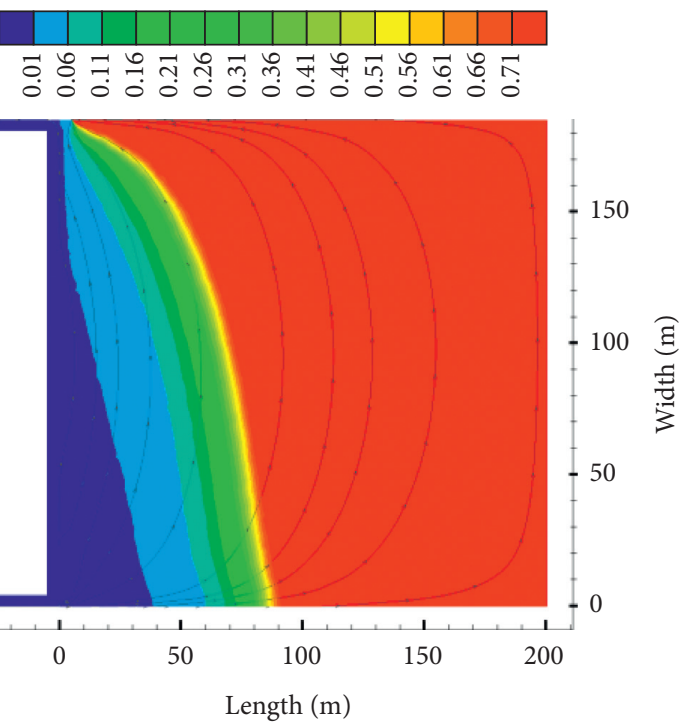

(b)

Gas concentration:

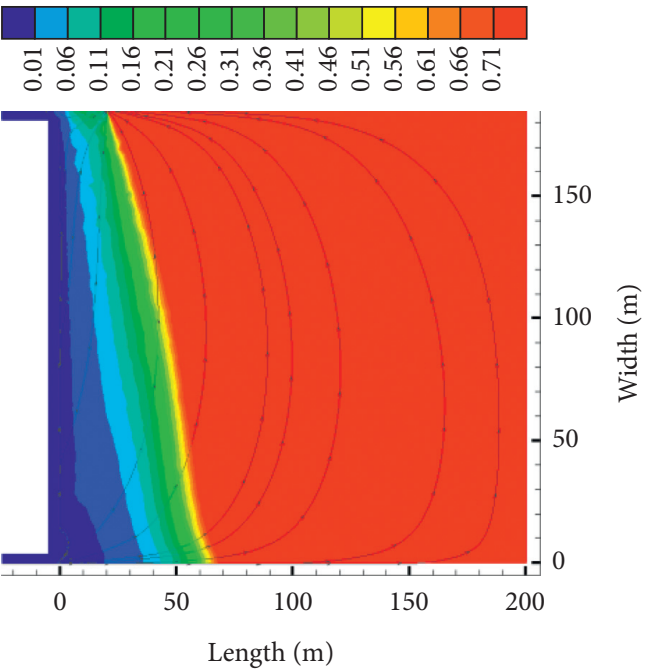

(c)

FIGURE 5: Gas distribution in goaf under different parameters. (a) Gas distribution in goaf without drainage. (b) Gas distribution under the condition of drainage $\left(x=10 \mathrm{~m}, v=3 \mathrm{~m} \cdot \mathrm{s}^{-1}\right)$. (c) Gas distribution in goaf without drainage $\left(x=20 \mathrm{~m}, v=5 \mathrm{~m} \cdot \mathrm{s}^{-1}\right)$.

surface, the higher the gas concentration in the borehole. The gas concentration was in the range from 20 to $60 \%$. Simultaneously, the gas concentration gradient gradually dropped.

In Figure 6(b), the blue area represents the zone where the gas concentration in the upper corner was below $0.8 \%$. It can be observed that the gas concentration in the upper corner gradually decreased as the extraction rate increased. When the borehole extraction rate was lower than $3 \mathrm{~m} \cdot \mathrm{s}^{-1}$, the upper corner's gas concentration decreased faster than that when the extraction rate exceeded $3 \mathrm{~m} \cdot \mathrm{s}^{-1}$. When the borehole was located $10 \mathrm{~m}$ behind the working face, the gas concentration in the upper corner was the lowest, and the extraction effect was the best. The farther the borehole from the working surface, the weaker the ability to control the upper corner. When the borehole was $20 \mathrm{~m}$ away from the working surface, the extraction rate exceeded $6 \mathrm{~m} \cdot \mathrm{s}^{-1}$, ensuring that the upper corner gas concentration was less than $0.8 \%$.

The analysis of Figures 5 and 6 and fitting formula (14) revealed that the negative pressure of the borehole changed the distribution of the gas flow field in the goaf. Part of the gas that was directly pumped out contributed to intercepting the gas gushing out of the goaf. Simultaneously, it disturbed the eddy currents formed in the upper corners of the working surface and prevented the local gas accumulation under certain conditions of extraction flow and drilling positions. However, the negative pressure also attracted high-concentration gas in the goaf to move closer to the working face, leading to increased air leakage from the 
TABLE 3: Design scheme of numerical simulation parameters.

\begin{tabular}{lc}
\hline Drilling location $(Y)(\mathrm{m})$ & Borehole gas velocity $(\mathrm{v})$ \\
\hline 5 & $1 \mathrm{~m} \cdot \mathrm{s}^{-1}, 2 \mathrm{~m} \cdot \mathrm{s}^{-1}, 3 \mathrm{~m} \cdot \mathrm{s}^{-1}, 4 \mathrm{~m} \cdot \mathrm{s}^{-1}, 5 \mathrm{~m} \cdot \mathrm{s}^{-1}, 6 \mathrm{~m} \cdot \mathrm{s}^{-1}, 7 \mathrm{~m} \cdot \mathrm{s}^{-1}$ \\
10 & $1 \mathrm{~m} \cdot \mathrm{s}^{-1}, 2 \mathrm{~m} \cdot \mathrm{s}^{-1}, 3 \mathrm{~m} \cdot \mathrm{s}^{-1}, 4 \mathrm{~m} \cdot \mathrm{s}^{-1}, 5 \mathrm{~m} \cdot \mathrm{s}^{-1}, 6 \mathrm{~m} \cdot \mathrm{s}^{-1}, 7 \mathrm{~m} \cdot \mathrm{s}^{-1}$ \\
15 & $1 \mathrm{~m} \cdot \mathrm{s}^{-1}, 2 \mathrm{~m} \cdot \mathrm{s}^{-1}, 3 \mathrm{~m} \cdot \mathrm{s}^{-1}, 4 \mathrm{~m} \cdot \mathrm{s}^{-1}, 5 \mathrm{~m} \cdot \mathrm{s}^{-1}, 6 \mathrm{~m} \cdot \mathrm{s}^{-1}, 7 \mathrm{~m} \cdot \mathrm{s}^{-1}$ \\
20 & $1 \mathrm{~m} \cdot \mathrm{s}^{-1}, 2 \mathrm{~m} \cdot \mathrm{s}^{-1}, 3 \mathrm{~m} \cdot \mathrm{s}^{-1}, 4 \mathrm{~m} \cdot \mathrm{s}^{-1}, 5 \mathrm{~m} \cdot \mathrm{s}^{-1}, 6 \mathrm{~m} \cdot \mathrm{s}^{-1}, 7 \mathrm{~m} \cdot \mathrm{s}^{-1}$ \\
25 & $1 \mathrm{~m} \cdot \mathrm{s}^{-1}, 2 \mathrm{~m} \cdot \mathrm{s}^{-1}, 3 \mathrm{~m} \cdot \mathrm{s}^{-1}, 4 \mathrm{~m} \cdot \mathrm{s}^{-1}, 5 \mathrm{~m} \cdot \mathrm{s}^{-1}, 6 \mathrm{~m} \cdot \mathrm{s}^{-1}, 7 \mathrm{~m} \cdot \mathrm{s}^{-1}$ \\
30 & $1 \mathrm{~m} \cdot \mathrm{s}^{-1}, 2 \mathrm{~m} \cdot \mathrm{s}^{-1}, 3 \mathrm{~m} \cdot \mathrm{s}^{-1}, 4 \mathrm{~m} \cdot \mathrm{s}^{-1}, 5 \mathrm{~m} \cdot \mathrm{s}^{-1}, 6 \mathrm{~m} \cdot \mathrm{s}^{-1}, 7 \mathrm{~m} \cdot \mathrm{s}^{-1}$ \\
\hline
\end{tabular}

working face. This increased the gas concentration gradient on the return air side, leading to a higher risk of spontaneous combustion in the goaf.

\subsubsection{Influence of Large-Diameter Borehole Extraction on} Spontaneous Combustion Zone in Goaf. When the gas in the goaf is subjected to high-flow extraction, the air leakage state in the goaf will change, varying the width of the oxidation zone and the air leakage in the goaf. In this paper, the oxygen concentration in the goaf was used as a zoning criterion. The area with the oxygen concentration exceeding $18 \%$ in the goaf was identified as a heat dissipation zone, while that with the oxygen concentration in the goaf between 8 and 18\% was regarded as an oxidation heating zone. The oxygen concentration in the goaf area in the breath zone was less than $8 \%$. To study the distribution law of the spontaneous combustion zone in the goaf, the distribution variation of the spontaneous combustion zone was compared when the borehole was located at different positions under the condition that the extraction rate of the large-diameter borehole was $6 \mathrm{~m} \cdot \mathrm{s}^{-1}$. In addition, the distribution variation of the spontaneous combustion zones in the goaf under the condition of different extraction rates of the large-diameter borehole was compared when the borehole was located at $10 \mathrm{~m}$.

At $Z=2$, there was no extraction; when the borehole was located at $10 \mathrm{~m}$, the extraction rate was $6 \mathrm{~m} \cdot \mathrm{s}^{-1}$. When the borehole was located at $20 \mathrm{~m}$, the oxygen concentration distribution cloud diagram was obtained, as shown in Figure 7.

According to the numerical simulation results on oxygen distribution in Tables 4 and 5 and the cloud diagram in Figure 7, larger drilling depths in the goaf corresponded to larger extraction rate, wider spontaneous combustion zone of the goaf, and higher risk of spontaneous combustion.

The disturbance effect of the extraction of large-diameter boreholes caused the spontaneous combustion zone of the goaf to widen and get deeper in the goaf. Therefore, the risk of spontaneous combustion in the goaf increased. The simulation demonstrated that when the borehole was located at a position of $20 \mathrm{~m}$, the mixed gas extraction rate of the borehole was $6 \mathrm{~m} \cdot \mathrm{s}^{-1}$, the maximum width of the spontaneous combustion zone in the goaf was $30 \mathrm{~m}$, and the shortest spontaneous combustion period of the coal seam of the Tenghui Coal Mine was $35 \mathrm{~d}$. This implied that the safe advance rate of the working face was no less than $0.86 \mathrm{~m}$ per day.

\section{Field Test Results}

According to the numerical simulation results, when the flow rate of the extraction borehole was no less than $3 \mathrm{~m} \cdot \mathrm{s}^{-1}$, the borehole located in the range of $5 \mathrm{~m}-15 \mathrm{~m}$ behind the working face inhibited the gas accumulation in the upper corner of the working face. At the flow rate of the extraction borehole no less than $7 \mathrm{~m} \cdot \mathrm{s}^{-1}$, the borehole located $[5 \mathrm{~m}$, $20 \mathrm{~m}$ ] from the working face could inhibit the gas accumulation in the upper corner of the working face. However, the flow rate of $7 \mathrm{~m} \cdot \mathrm{s}^{-1}$ was the maximum limit value that could be assigned to a large-diameter drilling pipeline of the extraction system.

The 2-105 working face was located southwest of the mine field. As the second working face of the first mining area of the mine, it was arranged in the west wing of the first mining area, east-west direction. On the east wing of the working face was the return air roadway, belt transportation lane, and auxiliary transportation lane of the first mining area. The south and west wings were the boundaries of the coal mine field, and the north wing was the 2-104 working face. Combined with the simulation results and the actual conditions of the Tenghui Mine's 2-105 working face, the extraction borehole was designed. The construction site was located in the 2-105 adjacent roadway, which was the preparation roadway for the next working face. The dimensions of the adjacent roadway of the working face were $3 \mathrm{~m} \times 3 \mathrm{~m} \times 4 \mathrm{~m}$, and the roadway length was $800 \mathrm{~m}$.

The engineering design implied a borehole interval (spacing) of $10 \mathrm{~m}$ and a borehole distance of $2 \mathrm{~m}$ from the floor, considering the production operability and safety. When the extraction borehole entered the goaf and was located $5 \mathrm{~m}$ from the working face, the control valve was opened for gas extraction, while the borehole located $15 \mathrm{~m}$ from the working face was closed. The control valves of subsequent boreholes were operated in turn, and the flow rate of the extraction borehole was no less than $3 \mathrm{~m} \cdot \mathrm{s}^{-1}$. The boreholes were numbered in increasing order with the distance from the working face, as shown in Figure 8.

With the advance of the working face, when the $1 \#$ borehole connected to the goaf entered the goaf and was $5 \mathrm{~m}$ from the working face, the $1 \#$ borehole control valve was opened for gas extraction. When the 2\# borehole entered the goaf and was $5 \mathrm{~m}$ from the working face, the 2\# borehole control valve was opened for gas extraction, and the $1 \#$ borehole control valve was closed simultaneously. The alternate switching of boreholes was similar to the subsequent drilling. 


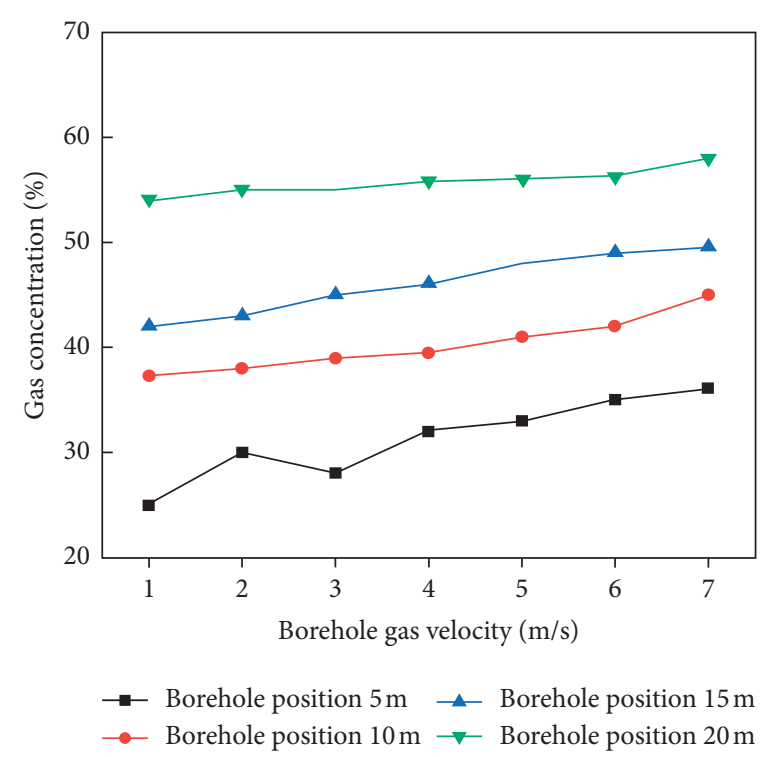

(a)

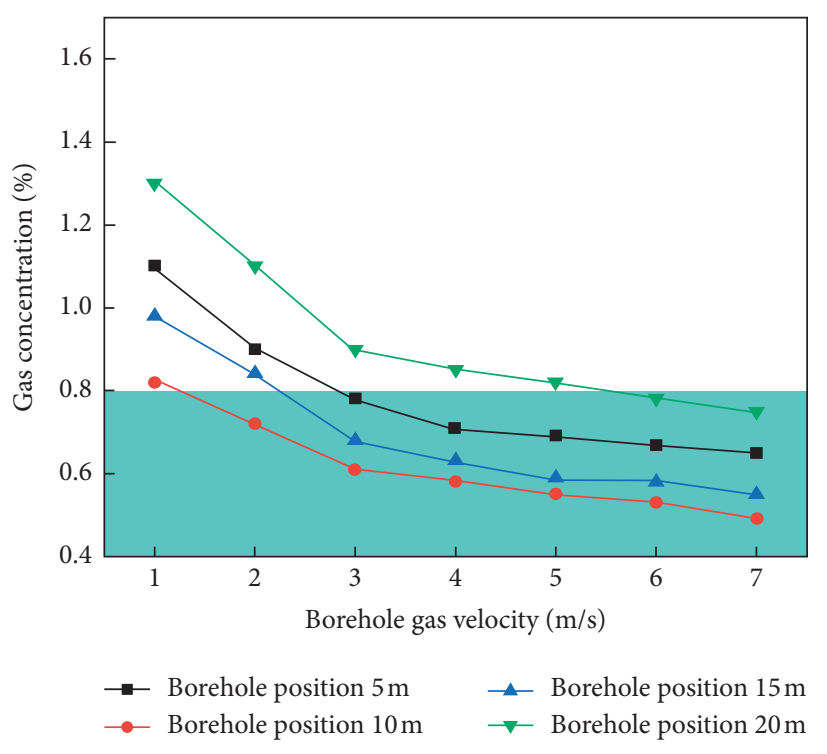

(b)

FIgURE 6: Gas concentration of extraction borehole and upper corner under different parameters. (a) Gas concentration in drainage pipeline. (b) Gas concentration in upper corner.

After the 1\#, 2\#, and 3\# large-diameter boreholes started the gas extraction, the gas concentrations in the extraction pipeline, the upper corner, and the return air roadway were recorded per each $1 \mathrm{~m}$, as the working face advanced.

According to the performed investigation of three boreholes, the gas concentration in the upper corner of the working face and the return air roadway was within the controllable range, the gas concentrations in the upper corner and the return air roadway ranged between 0.5 and $0.8 \%$ and between 0.45 and $0.61 \%$, respectively. As the working face advanced, with an increase of the distance between the working face and the large-diameter borehole, the evolution curves of gas concentration in the upper corner of the working face and the return air roadway were "V"-shaped. When the borehole was $5 \mathrm{~m}$ away from the working face, the gas concentrations in the upper corner and the return air roadway reached their maximal values of 7 and $0.6 \%$, respectively. When the borehole was about $12 \mathrm{~m}$ away from the working face, the borehole had the strongest control over the upper corner, the lowest gas concentration in the upper corner was about $0.55 \%$, and the gas concentration in the return air roadway was about $0.45 \%$. As the working face continued to advance, the gas concentration in the upper corner and the return air roadway gradually increased and changed periodically with the opening of the borehole. The variation trend of the gas concentration in the upper corner was consistent with the trend of the simulated data-fitting equation.

The gas concentration in the large-diameter borehole gradually increased. The deeper the borehole into the goaf, the higher the gas concentration in the borehole. When the borehole was located in the shallow part of the goaf, i.e., about $5 \mathrm{~m}$ behind the working face, the negative pressure around the borehole was relatively low, and the gas injection in the goaf was relatively small. The gas concentrations in the pipeline and the upper corner were about 15 and $0.6 \%$, respectively. When the borehole was located $12 \mathrm{~m}$ behind the coal mining face, the gas concentration reached the highest value of about $37 \%$. At this time, the gas concentration in the upper corner was maintained at about $0.55 \%$, and then the gas flow in the pipeline tended to be stable. Meanwhile, the gas concentration in the borehole changed periodically with the conversion of the borehole.

The comparative analysis of Figures $8(\mathrm{a})$ and $8(\mathrm{~b})$ revealed that there was a certain relationship between gas concentrations in the extraction pipeline, the upper corner, and the return air roadway, i.e., when the gas concentration in the extraction pipeline increased, the gas concentration in the upper corner and the return air roadway tended to decrease.

The extraction flow and borehole spacing determined by the numerical simulation were verified in practice And, when the drilling hole was $10 \mathrm{~m}-12 \mathrm{~m}$ behind the working face, the extraction effect had been the best effect. During the actual advancement of the working face, the corresponding relationships between the advancing distance and the gas concentration in the upper corner, gas extraction volume, and gas concentration in the return air roadway were observed, and the operation model's specific parameters in this particular mine were derived.

The main innovation of this paper is that it substantiated and successfully implemented a large-diameter $(550 \mathrm{~mm})$ borehole in the roadway adjacent to the working face to control the gas accumulation. To the best of the authors' knowledge, boreholes with a diameter not exceeding $300 \mathrm{~mm}$ have been applied yet for this purpose. According to the relevant definition [30], the underground large-diameter hole generally refers to the near horizontal hole with the final 


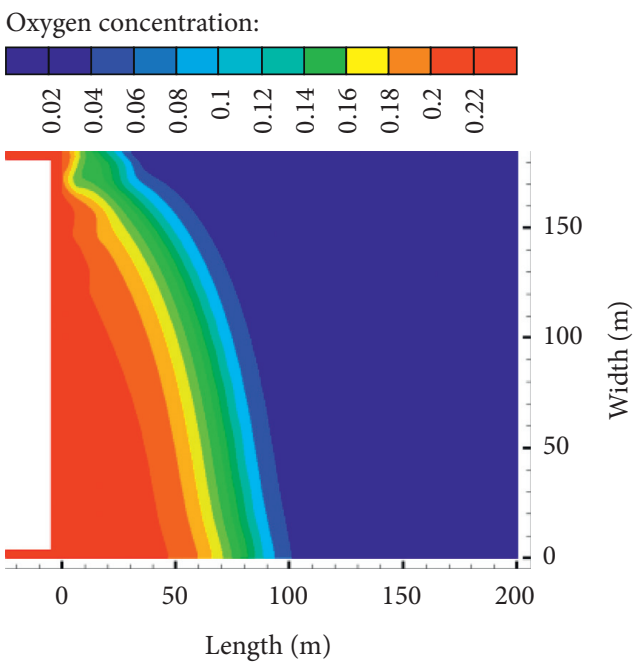

(a)
Oxygen concentration:

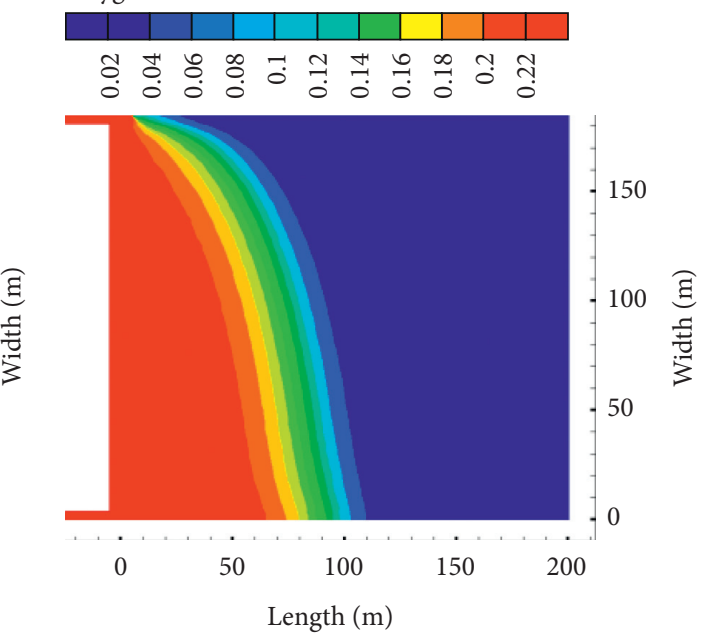

(b)

Oxygen concentration:

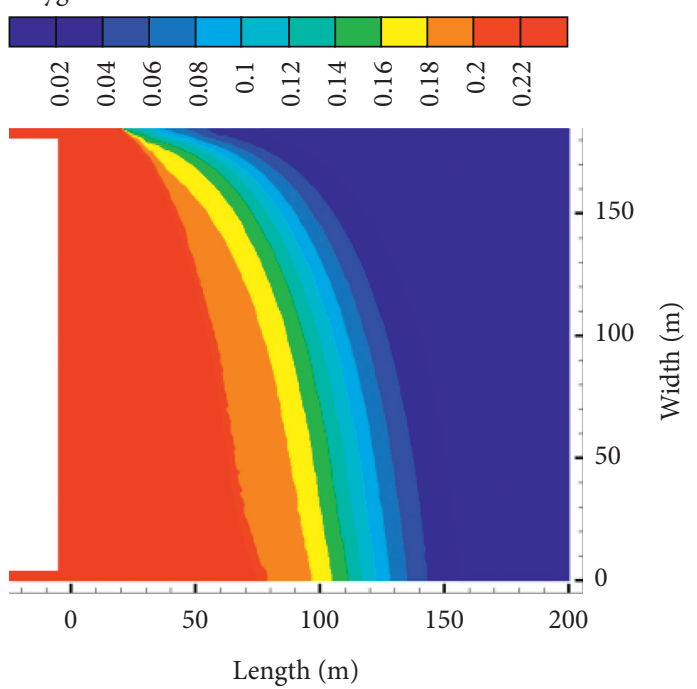

(c)

Figure 7: Distribution of spontaneous combustion zone in goaf. (a) Oxygen distribution without pumping. (b) Oxygen distribution $\left(x=10 \mathrm{~m}, v=6 \mathrm{~m} \cdot \mathrm{s}^{-1}\right)$. (c) Oxygen distribution $\left(x=20 \mathrm{~m}, v=6 \mathrm{~m} \cdot \mathrm{s}^{-1}\right)$.

TABle 4: Distribution of spontaneous combustion zone in goaf at different positions $\left(v=6 \mathrm{~m} \cdot \mathrm{s}^{-1}\right)$.

\begin{tabular}{lccc}
\hline Extraction location $(\mathrm{m})$ & Inlet side $(\mathrm{m})$ & Middle part $(\mathrm{m})$ & Air-return side $(\mathrm{m})$ \\
\hline No extraction & $65-85$ & $53-75$ & $18-35$ \\
5 & $67-88$ & $70-96$ & $11-25$ \\
10 & $69-91$ & $73-100$ & $16-30$ \\
15 & $73-93$ & $76-105$ & $22-33$ \\
20 & $75-95$ & $80-110$ & $25-36$ \\
\hline
\end{tabular}

TABLE 5: Distribution of spontaneous combustion zone in goaf with different extraction rates $(y=10 \mathrm{~m})$.

\begin{tabular}{lccc}
\hline Extraction rate $\left(\mathrm{m} \cdot \mathrm{s}^{-1}\right)$ & Inlet side $(\mathrm{m})$ & Middle part $(\mathrm{m})$ & Air-return side $(\mathrm{m})$ \\
\hline 2 & $64-87$ & $69-93$ & $12-23$ \\
4 & $66-89$ & $72-96$ & $15-27$ \\
\hline
\end{tabular}




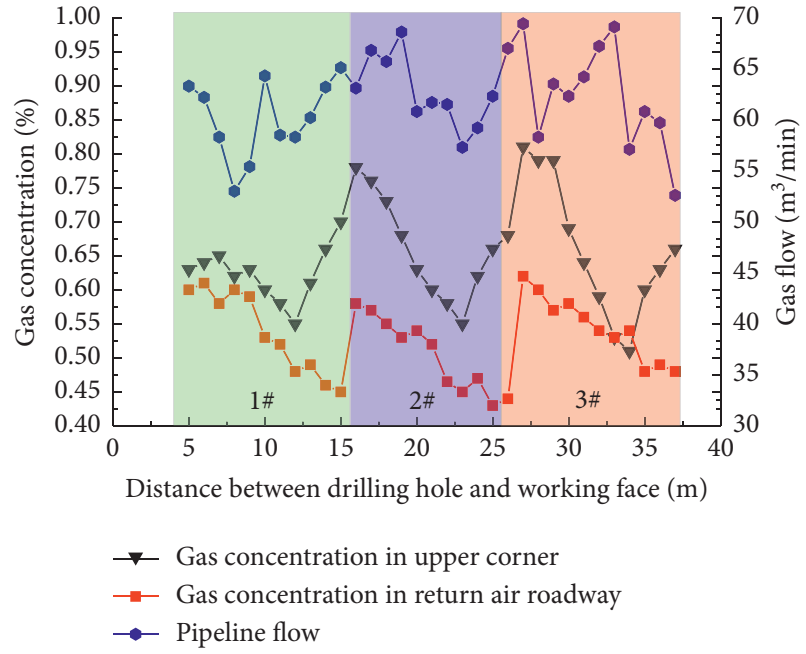

(a)

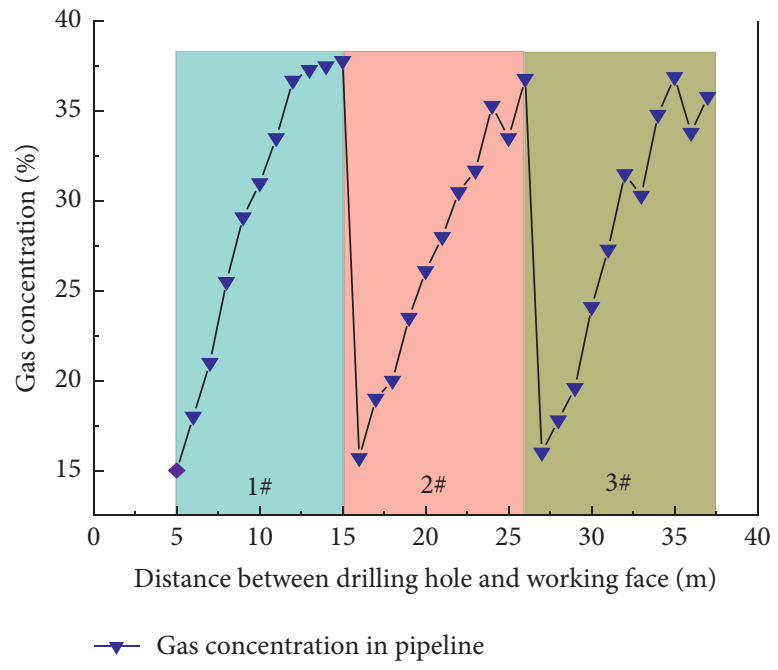

(b)

FIGURE 8: Variation of gas concentration in the upper corner, borehole, and return air roadway with the advance of the working face under drainage conditions.

hole diameter of more than $200 \mathrm{~mm}$, which is used for pipeline laying (including ventilation pipe, gas drainage pipe, and drainage pipe), through tunnel rescue (for provision, drainage, escape, etc.) and gas drainage. Thus, the adopted borehole diameter of $550 \mathrm{~mm}$ corresponds to largediameter definition, while larger diameter values are envisaged to be tested in the follow-up study.

\section{Conclusions}

This study analyzed the gas accumulation patterns caused by the development of fissures in the goaf of the fully mechanized working face, gas storage, and the formation of eddy current in the upper corner. It introduced a technical scheme of gas control in the goaf, which used the adjacent roadway large-diameter boreholes, analyzed gas migration law in the goaf, and determined the optimal configuration parameters.

(1) Within the CFD framework, firstly, a borehole gas flow simulation scheme was designed under the conditions of different borehole locations and extraction rates. Then, the optimal position of largediameter drilling was determined through simulation.

(2) Next, the influence of large-diameter borehole drainage on the spontaneous combustion zone of the goaf was analyzed. Therefore, the optimal drilling configuration parameters based on the upper corner gas concentration in the fully mechanized mining face of the Tenghui Mine were determined: the velocity of the borehole was no less than $3 \mathrm{~m} \cdot \mathrm{s}^{-1}$, the effective range of the borehole placement was $5 \mathrm{~m}-15 \mathrm{~m}$ behind the working face, and the advance rate of the working face was no less than $0.86 \mathrm{~m}$ per day.
(3) The engineering parameters were designed according to the numerical simulation results. By investigating the three boreholes' extraction parameters, it was determined that this process could effectively mitigate the local gas overrun in the target mine. The gas concentration in the upper corner was controlled below $0.8 \%$. The gas concentration in the return air roadway was controlled below $0.65 \%$, which was in line with the coal mine safety regulations' relevant provisions.

(4) A part of the emitted gas entered the extraction system, which ensured the comprehensive utilization of gas as a clean energy source and provided a solution for similar mines to mitigate gas emission problems.

\section{Data Availability}

All data and models used to support the findings of this study are available from the corresponding author upon request.

\section{Conflicts of Interest}

The authors declare that there are no conflicts of interest.

\section{References}

[1] Y.-P. Cheng, L. Wang, and X.-L. Zhang, "Environmental impact of coal mine methane emissions and responding strategies in China," International Journal of Greenhouse Gas Control, vol. 5, no. 1, pp. 157-166, 2011.

[2] A. Majdi, F. P. Hassani, and M. Y. Nasiri, "Prediction of the height of destressed zone above the mined panel roof in longwall coal mining," International Journal of Coal Geology, vol. 98, pp. 62-72, 2012. 
[3] H. Guo, L. Yuan, B. Shen, Q. Qu, and J. Xue, "Mining-induced strata stress changes, fractures and gas flow dynamics in multi-seam longwall mining," International Journal of Rock Mechanics and Mining Sciences, vol. 54, pp. 129-139, 2012.

[4] H. B. Zhang and Y. F. Huang, "Flow field and gas concentration distribution in the coal mining face and mined-out area with J-shape and U-shape ventilation system using Comsol," Journal of Physics: Conference Series, vol. 1168, no. 5, Article ID 052041, 2019.

[5] H. W. Zhou, J. F. Liu, D. J. Xue, H. Y. Yi, and J. H. Xue, "Numerical simulation of gas flow process in mining-induced crack network," International Journal of Mining Science and Technology, vol. 22, no. 6, pp. 793-799, 2012.

[6] C. O. Karacan and G. S. Esterhuizene, "Reservoir simulationbased modeling for characterizing longwall methane emissions and gob gas vent hole production," International Journal of Coal Geology, vol. 71, no. 2-3, pp. 225-245, 2007.

[7] Y. W. Wang, W. J. Yan, Z. J. Ren, Z. Q. Yan, Z. Liu, and $\mathrm{H}$. Zhang, "Investigation of large-diameter borehole for enhancing permeability and gas extraction in soft coal seam," Geofluids, vol. 6, pp. 1-3, 2020.

[8] L. Yuan, H. Guo, P. Li, and Y. P. Lian, "Theory and technology of goaf gas drainage with large-diameter surface boreholes," Journal of China Coal Society, vol. 38, no. 1, pp. 1-8, 2013.

[9] Y. P. Cheng, D. Y. Zhou, and Q. X. Yu, "Research on extraction and emission laws of gas for pressure-relief in protecting coal seams," Journal of Mining \& Safety Engineering, vol. 23, no. 1, pp. 13-19, 2006.

[10] M. Yang and J. L. Gao, "Numerical simulation of the gas distribution in the gobs of u-type and Y-type ventilation mining workfaces," International Journal on Computer Science and Engineering, vol. 9, no. 1-2, pp. 147-152, 2012.

[11] T. K. Lu, H. Yu, T. Zhou, J. Mao, and B. Guo, "Improvement of methane drainage in high gassy coal seam using waterjet technique," International Journal of Coal Geology, vol. 79, no. 1-2, pp. 40-48, 2009.

[12] S. L. Kong, Y. Cheng, T. Ren, and H. Y. Liu, “A sequential approach to control gas for the extraction of multi-gassy coal seams from traditional gas well drainage to mining-induced stress relief," Applied Energy, vol. 131, pp. 67-78, 2014.

[13] C. Zhang, S. H. Tu, and Y. X. Zhao, "Compaction characteristics of the caving zone in a longwall goaf: a review," Environmental Earth Sciences, vol. 78, no. 1, 2019.

[14] V. T. Presler, "Modeling of air-gas and dynamic processes in driving development workings in the gas-bearing coal seams," Journal of Mining Science, vol. 38, no. 2, pp. 168-176, 2002.

[15] M. G. Qian and J. L. Xu, "Study on the "O shape" circle distribution characteristics of mining-induced fractures in the overlaying strata," Journal of China Coal Society, vol. 23, no. 5, pp. 466-469, 1998, in Chinese.

[16] H. P. Kang, J. Lou, F. Gao, J. Yang, and J. Z. Li, “A physical and numerical investigation of sudden massive roof collapse during longwall coal retreat mining," International Journal of Coal Geology, vol. 188, pp. 25-36, 2018.

[17] S. Wang, D. Wang, K. Cao, S. Wang, and Z. Pi, "Distribution law of 3D fracture field of goaf and overlying strata," Journal of Central South University (Science and Technology), vol. 45, pp. 833-839, 2014.

[18] Y. M. Wang, X. Q. Li, and Z. X. Guo, "Prediction of selfignition fire propagation and coal loss in an inclined seam," Heat Transfer Research, vol. 49, no. 9, pp. 827-845, 2018.

[19] J. Ma, Y. S. Sun, and B. W. Li, "Simulation of combined conductive, convective and radiative heat transfer in moving irregular porous fins by spectral element method," International Journal of Thermal Sciences, vol. 118, pp. 475-487, 2017.

[20] Y. Nakayama, Introduction to Fluid Mechanics, ButterworthHeinemann, Oxford, UK, 2nd edition, 2018.

[21] H. Darcy, Les Fontaines Publiques de la Ville de DIJON: Exposition et Application, Victor Dalmont, Kraljevica, Croatia, 1856.

[22] J. Kozeny, "Ueber kapillare leitung des wassers im boden," Sitzungsberichte der Kaiserlichen Akademie der Wissenschaften, vol. 136, pp. 271-306, 1927.

[23] P. C. Carman, "Fluid flow through granular beds," Transactions of the Institution of Chemical Engineers, vol. 15, pp. 150-166, 1937.

[24] G. Wang, H. Xu, M. M. Wu, Y. Wang, R. Wang, and X. Q. Zhang, "Porosity model and air leakage flow field simulation of goaf based on DEM-CFD," Arabian Journal of Geosciences, vol. 11, no. 7, p. 148, 2018.

[25] L. Lunarzewski and W. Les, "Gas emission prediction and recovery in underground coal mines," International Journal of Coal Geology, vol. 35, no. 1-4, pp. 117-145, 1998.

[26] G. Dai, Y. Wang, C. Zhang, Q. Li, and G. Shao, "Forecast of the gas effused from the face in protective seam," Journal of China Coal Society, vol. 32, no. 4, p. 382, 2007.

[27] Z. Qin, L. A. Yan, H. Guo et al., "Investigation of longwall goaf gas flows and borehole drainage performance by CFD simulation," International Journal of Coal Geology, vol. 150-151, pp. 51-63, 2015.

[28] L. M. Yuan and A. C. Smith, "Numerical study on effects of coal properties on spontaneous heating in longwall gob areas," Fuel, vol. 87, no. 15-16, pp. 3409-3419, 2008.

[29] C. G. Speziale, T. B. Gatski, and M. M. Nessan Fitzmaurice, "An analysis of RNG-based turbulence models for homogeneous shear flow," Physics of Fluids A: Fluid Dynamics, vol. 3 , no. 9, pp. 2278-2281, 1991.

[30] Z. J. Shi, J. L. Liu, and Q. X. Li, "Development and application of drilling technique and equipment in coal mining area of China," Coal Science and Technology, vol. 46, no. 1, pp. 1-6, 2018. 